\title{
EVALUATING TREATMENT-SEEKING BEHAVIOR AND THE RELATED FACTORS AMONG THE DWELLERS OF SAFASHAHR CITY
}

\author{
SAREH RASHIDI ${ }^{1,2}$, ABBAS YAZDANPANAH ${ }^{2 *}$, PARVIZAGHAYIIBARZABAD ${ }^{3}$ \\ ${ }^{1}$ Department of Healthcare Management, Fars Science and Research Branch, Islamic Azad University, Marvdasht, Iran. ${ }^{2}$ Department of \\ Healthcare Management, Islamic Azad University, Marvdasht Branch, Marvdasht, Iran. ${ }^{3}$ Department of Social Determinants of Health \\ Research Center, Yasouj University of Medical Sciences, Yasouj, Iran. Email: abbas_yaz@yahoo.com
}

Received: 04 August 2016, Revised and Accepted: 23 September 2016

\section{ABSTRACT}

Objective: The present study aims to recognize and evaluate treatment-seeking behavior and the related factors among the dwellers of Safashahr city.

Methods: The current applied research is cross-sectional with a population size of 380 and executed in a systematic random sampling among the dwellers of Safashahr city and the villages governed by it. SPSS version 22 has been utilized for analyzing the data in this study. T-test, Chi-square variance analysis, Pearson test, and Spearman test have been used to evaluate the significance and the relationship between the understudy variables with the treatment-seeking variables.

Results: $75 \%$ of participants in the study have reported being diagnosed with illness in the past 6 months. Visiting family physician was ranked highest with an average 3.36 followed by public hospitals with an average of 3.05. However, they chose to go to clinic centers with an average of 2.1. Self-medication has been reported for an average of $2.6 \%$ and $88.2 \%$ of the participants in this study have preferred to ignore the medium and less than medium treatment. In this study, a significant relationship has been found between age, number of family members, living location, salary, habitation status, and type of insurance with at least one of the search-for-treatment $(\mathrm{p}<0.05)$

Conclusion: Taking into account the findings of the research, lifting the society's awareness about the consequences of self-medication and ignorance toward treatment, continuing and executing the urban family physician in other areas, implementation of measures for limiting access to unprescribed medications, increasing satisfaction, and trust toward public sector and provision and allocation of health resources across cities are recommended as appropriate solutions to improving the pattern of using health services.

Keywords: Treatment seeking behavior, Self-medication.

(c) 2017 The Authors. Published by Innovare Academic Sciences Pvt Ltd. This is an open access article under the CC BY license (http://creativecommons. org/licenses/by/4. 0/) DOI: http://dx.doi.org/10.22159/ajpcr.2017.v10i1.14500

\section{INTRODUCTION}

Health and its supply is one of the issues which has been considered by human since past time and today supplying treatment services is undertaken by all governments [1]. Limited resources and facilities are facts, with which treatment services systems are encountered and each answer differently to these shortages. Many patients and their family attendants had always been seeking effective treatments from various sources. These efforts even increase when the patients did not receive suitable treatment answer from their physician [2].

It should be said that besides this fact that access and using treatment services is a public right, but sometimes some inequalities are observed in access to these services which shows that the patients who are from lower social and economic positions and nationalities and minorities have less benefit from these advantages [3]

Various people of society regarding several factors such as age gender, social position, severity and type of illness, accessible services, awareness, and the quality of provided services, in encountering with disease and illness show different behaviors that these behaviors are called treatment-seeking behaviors [5]. In other words, treatmentseeking behavior is the usual habit of people which is the result of contrast and balance between health needs, health resources and cultural, economic, social, political, national, and international factors [6]. This behavior in collective and massive level could organize the demand for utilizing health treatment services and intensely impact it [5].

Cognition of factors effective on services consumption is a very important economic and health issue [7], so cognition of behavior state in seeking care in every society will help optimal distribution and designating of health-care resources and since treatment-seeking behavior is a continuous and dynamic process which is influenced by internal and external factors [8] that internal factors include cases such as problem perception and sense of need to specialized attention and external factors include cases which are effective on the person decision in using services such as the place of providing service [5], better perception of external factors influential in people decision-making is very significant in evaluating the performance of policies relating to access to health system [7]. Designation of sufficient resources for health section could improve mortality statistics [9]. Awareness of treatment-seeking behavior could include total rate of benefiting from health-care services and also special information in this ground that who use what kind of health-care services and this service is provided from which source [10]. Generally, 69\% of total cost of health section is highly influenced by consumption behavior [11]. It should be said that using health-care services could be observed as a type of individual behavior and behavioral sciences try to explain and examine individual behavior as a function of their traits and environmental traits the individual live in it and create a special framework [12]. Guideline policies are adjusted in all health-care systems based on information relating to health promotion and treatment-seeking behavior and factors effective on it [6]

Health is a vital need of all men and planning about people just access to this vital need and attention to demand of various groups of society for organizing health services presentation is a very important issue and depends on identifying people behavior in treatment seeking. The present study is performed with the aim of examining treatmentseeking behavior and recognizing consumption patterns of Safashahr 
habitants in 2015 to be a guideline for policy makers and health authorities of the university and city for appropriate designation and use of health resources.

\section{METHODS}

The study was descriptive and analytical which was conducted in a cross-sectional method in 2015 in Safashahr city and covered villages in Fars province. This city has 38,238 persons population and families are covered by two health centers. Region 1 health center services 18,870 persons of urban population and 3272 persons of rural population, and region 2 health center services 11,758 persons of urban population and 4338 persons of rural population. Since the neighboring villages are covered by centers of region 1 and 2 were considered among the research statistical society. Regarding Morgan table, 380 persons above 18 years old from rural and urban families were selected. Proportionate to population and by regular random method and based on the family record number, 188 persons from urban families of region 1 and 117 persons from urban families of region 2 were selected. Regarding that 5 villages were covered by region 1 heath center and 5 villages covered by region 2 , two villages were selected by simple random method from both centers and by regular random method, and based on the family record file in health center, 32 persons from region 1 and 43 persons from region 2 were selected.

For access to all family people, especially employees and the family practitioners, families are referred to in non-departmental hours and evenings. The first family member above 18 years old who visits the questioner at his house door enters the study with consent and in case of lack of presence or tendency of people to enter the study; the neighboring house is selected as sampling unit.

Data collecting tool was Pourreza study questionnaire that some changes were made in it based on the study setting features and studied variables. This questionnaire includes two groups of questions that in the first section, we examined demographic information (age, gender, marital status, place of living, education level, occupation status, and the number of people in the family), economic information (habitancy status, family monthly income, and insurance status), and other background information which are supposed could be among factors relating to treatment-seeking behavior and the second part is related to dedicated questions. Behavior dedicated questions are seeking to treat people from different dimensions including suffering from acute and chronic disease in the past 6 months, the rate of illness intensity, the performed treatment measurements, consulting during illness, referring to therapist in various stages of illness, the first units people refer for receiving health services, completion of treatment period, reasons of non-emphasis on illness, and self- medication reasons.

For confirming the questionnaire reliability, experts and professors' views were used. For this purpose, the questionnaire and aims and hypotheses were sent to professors and corrective views were declared at the end of the questionnaire. Final questionnaires were prepared after applying professors' views. For determining the questionnaire reliability, test-retest method was used. The questionnaire was distributed among 30 persons, and after receiving answers, data were entered SPSS 22 software. With a 2-week time space, the questionnaire was again distributed among the same 30 persons and the obtained data entered SPSS software. Changes of the two stages answers were examined through intraclass coefficient test. Validity coefficient was reported 0.78 . The validity rate was confirmed, and the questionnaire became definitive and was used for data collecting.

The plan was approved by research Vice-chancellor of Marvdasht Islamic Azad University, and the required license was obtained from Shiraz Medical Sciences University.

All ethical cases were considered in performing the research. These cases included confidentiality of identity and information of participants and providing the required explanations for people participating in the study for familiarity with the study aim. Furthermore, all people who were selected for the study were quite free to fill the questionnaire and giving information and in case of dissatisfaction, people were omitted from the study and another person from this same family or neighboring house was replaced.

Data after collecting entered SPSS 22 software and were analyzed. Qualitative variables were provided as median and standard deviation and quantitative data as number (percent). For data analysis, based on variables, independent t-test, Chi-square and variance analysis Pierson correlation coefficient, and Spearman were used. The significance level in all analysis was considered less that $0.05 \%$.

\section{Findings}

Table 1 shows the demographic features of studied population. The average age of studied people was $36 \pm 13.5$. The youngest studied person was 18 and the oldest was 88 years old. Most studied people were women $(51.3 \%)$ and married (67.6\%). 3-4-person families had designated the highest percent (59.7\%) and families above 7 persons the lowest percent (4.5\%). $80 \%$ of people were living in cities and the rest in villages. Other demographic and economic specifications of people are shown in Tables 1 and 2.

The studies performed in this ground considered different times for estimating illness accession (13-15). In this study, like Boerema et al. study, illness accession rate has been evaluated based on answering to this question (have you been sick in the last 6 months?). Among 380 participants in the study, 287 persons have reported suffering from illness in the last 6 month. Therefore, illness accession rate is estimated $75.5 \%$. From this, $70.7 \%$ reported suffering from acute illness and $29.3 \%$ chronic illness. $39 \%$ of diseases were not intense and just $13.3 \%$ have declared high illness intensity. Most people reference is to family physician with average 3.36 and governmental hospital with average 30.5 . People normally $2.6 \%$ self-medicate and the rate

Table 1: Studied people distribution based on demographic specifications

\begin{tabular}{|c|c|c|c|}
\hline Studied features & Division & $\begin{array}{l}\text { Relative } \\
\text { frequency }\end{array}$ & $\begin{array}{l}\text { Absolute } \\
\text { frequency }\end{array}$ \\
\hline \multirow[t]{2}{*}{ Gender } & Male & 48.7 & 185 \\
\hline & Female & 51.3 & 195 \\
\hline \multirow[t]{3}{*}{ Age } & $<30$ years & 39.2 & 149 \\
\hline & $31-60$ & 54.5 & 207 \\
\hline & $>60$ years & 6.3 & 24 \\
\hline \multirow[t]{4}{*}{ Marital status } & Married & 67.6 & 257 \\
\hline & Single & 27.1 & 103 \\
\hline & Divorced & 1.8 & 7 \\
\hline & Died & 3.4 & 13 \\
\hline \multirow{2}{*}{ Place of living } & City & 82.4 & 313 \\
\hline & Village & 17.6 & 67 \\
\hline \multirow[t]{5}{*}{ Educations } & Illiterate & 4.7 & 18 \\
\hline & Below diploma & 26.9 & 102 \\
\hline & Diploma & 28.9 & 110 \\
\hline & $\begin{array}{l}\text { Associate diploma } \\
\text { and bachelor }\end{array}$ & 32.9 & 125 \\
\hline & $\begin{array}{l}\text { Master's degree } \\
\text { and higher }\end{array}$ & 6.6 & 25 \\
\hline \multirow[t]{4}{*}{ Family members } & 1-2 persons & 10.8 & 41 \\
\hline & 3-4 persons & 59.7 & 227 \\
\hline & 5-6 persons & 24.7 & 94 \\
\hline & $>7$ persons & 4.5 & 17 \\
\hline \multirow[t]{6}{*}{ Occupation status } & Unemployed & 10.3 & 39 \\
\hline & Self-employed & 27.9 & 106 \\
\hline & $\begin{array}{l}\text { Employee and } \\
\text { retired }\end{array}$ & 20.7 & 79 \\
\hline & Student & 9.3 & 35 \\
\hline & Housekeeper & 26.3 & 100 \\
\hline & Soldier & 2.1 & 8 \\
\hline Total & & 100 & 380 \\
\hline
\end{tabular}


of their inattention to treatment is 2.2. Minimum rate of referring is, respectively, related to clinic, private hospital, and health-care centers.

In Table 3, the results obtained from examining the relation between referring to therapist behavior, self-medication, and inattention to treatment with age and the number of family people is provided. Based on Spearman's correlation coefficient test, there was an inverse relation between age variable and inattention to treatment behavior $(\mathrm{p}=0.25$, correlation coefficient $=-0.115$ ), in this sense that with age increase people are less unconsidered to treatment. Pearson's correlation coefficient confirmed the inverse relation between family number and the behavior of referring to a therapist $(p=0.008$, correlation coefficient $=-0.13$ ). This inverse relation means that with increasing of family members, people less refer to a therapist.

In Table 4, the behavior of referring to therapist and self-medication of people is provided based on demographic and economic features. Regarding the table results, we can say that the behavior of referring to therapist and self-medication is significantly different in two living places of city and village (since the results obtained from t-test validity is $<0.05$ ). People living in cities both more refer to therapist and more self-medicate. The amounts obtained from test validity in behavior of referring to therapist based on income status based on unilateral variance analysis are a rate $<0.05$. We can say that people with higher income less refer to therapist. The test validity relating to self-medication shows a lack of significant difference of self-medication based on income level. The test validity relating to self-medication behavior shows a lack of difference of self-medication based on income level. It means that people with different incomes statistically are similar in tending to self-medication.

The rates obtained from test validity in both treatment-seeking behaviors of referring to therapist and self-medication based on

Table 2: The studied people distribution based on economic features

\begin{tabular}{|c|c|c|c|}
\hline $\begin{array}{l}\text { Studied } \\
\text { features }\end{array}$ & Division & $\begin{array}{l}\text { Relative } \\
\text { frequency }\end{array}$ & $\begin{array}{l}\text { Absolute } \\
\text { frequency }\end{array}$ \\
\hline \multirow[t]{5}{*}{ Income rate } & $<700,000$ Toomans & 28.9 & 110 \\
\hline & $\begin{array}{l}\text { Between } 700,000 \\
\text { and } 1.5 \text { million }\end{array}$ & 49.7 & 189 \\
\hline & $\begin{array}{l}\text { Between } 1.5 \text { and } \\
2.3 \text { million }\end{array}$ & 14.5 & 55 \\
\hline & $\begin{array}{l}\text { Between } 2.3 \text { million } \\
\text { and } 3 \text { million }\end{array}$ & 5.8 & 22 \\
\hline & $>3$ million & 1.1 & 4 \\
\hline \multirow{2}{*}{$\begin{array}{l}\text { Habitancy } \\
\text { status }\end{array}$} & Owner & 82.4 & 313 \\
\hline & Tenant & 17.6 & 67 \\
\hline \multirow{5}{*}{$\begin{array}{l}\text { Insurance } \\
\text { status }\end{array}$} & Without insurance & 2.1 & 8 \\
\hline & Relief committee & 2.1 & 8 \\
\hline & Armed forces & 8.9 & 34 \\
\hline & Social security & 42.4 & 161 \\
\hline & Treatment services & 44.5 & 169 \\
\hline \multirow{2}{*}{$\begin{array}{l}\text { Complementary } \\
\text { insurance }\end{array}$} & Yes & 25.5 & 97 \\
\hline & No & 47.5 & 283 \\
\hline Total & & 100 & 380 \\
\hline
\end{tabular}

housing status based on t-test is a rate $<0.05$. We can say that tenant people moderately proceed for treatment (referring to therapist and self-medication).

Table 5 provides the results obtained from examining the behavior of inattention to treatment based on demographic and economic features. The rates obtained from test validity with Chi-square method indicate living place dependence to inattentive to treatment behavior. It means that in both living places, inattentive to treatment behavior is significantly different (since test validity is $<0.05$ ). Among city habitants, inattentive to treatment behaviors occurs more.

The amounts obtained from validity test by Chi-square method in the above table show that income level is not independent from inattentive to treatment behavior. In this sense that among people with various incomes, inattentive to treatment behavior is significantly different (since test validity is $<0.05$ ). People in the three low-income classes are more inattentive to treatment, and this event in people with high incomes occurs less.

Rates obtained from test validity with variance analysis in the above table indicate the correlation between insurance type and inattentive behavior to treatment. Among people with different insurances, inattentive to treatment behavior is significantly different (since test validity is $<0.05$ ). People covered by social security comparing other insurances were less inattentive to treatment and people covered by relief committee had the highest rate of inattention, while people with treatment services and armed force insurance more showed moderate view about inattention to treatment.

There was no significant difference between other demographic variables (gender, marital status, education level, and occupation status) with none of treatment-seeking behaviors

\section{DISCUSSION}

Previous texts and literature show that treatment seeking is a multidimensional issue and they provided several models such as Rosen Stoke health model, utilization model, and using Anderson services and young decision-making model and factors effective on treatment seeking behavior [8].

Anderson model (2005) identifies treatment-seeking behavior as a function of three groups of factors. Factors relating to need-like perceived heath status or illness level which is the most important factor in using health services according to previous studies, empowering factors, the present study economic factors (income, insurance status, and housing status) which may make using services easy or difficult for the individual are categorized in this group. Background factors such as demographic features such as age, gender, marital status, occupation, education, and family number seem to be relevant to people treatmentseeking behavior. All models try to create a concept from general dimensions of treatment-seeking behavior and factors effective on it.

The study findings showed that the highest people reference at the time of illness are to family physician with average 3.36 and governmental hospitals with average 3.05 . On average, people 2.6 self-mediate, but they less (2.1) refer to health-care centers. $88.2 \%$ of people participating in this study showed medium and low inattentive to treatment behavior, and only $11.8 \%$ are highly or very highly inattentive to treatment (average 2.2). In other studies, different results

Table 3: Examining people treatment seeking behavior based on age and family number

\begin{tabular}{|c|c|c|c|c|c|c|}
\hline \multirow{2}{*}{$\begin{array}{l}\text { Independent } \\
\text { variables }\end{array}$} & \multicolumn{2}{|c|}{ Inattention to treatment } & \multicolumn{2}{|c|}{ Self-medication } & \multicolumn{2}{|c|}{ Referring to therapist } \\
\hline & Test validity & $\begin{array}{l}\text { Pearson's correlation } \\
\text { coefficient }\end{array}$ & $\begin{array}{l}\text { Test } \\
\text { validity }\end{array}$ & $\begin{array}{l}\text { Pearson's correlation } \\
\text { coefficient }\end{array}$ & $\begin{array}{l}\text { Test } \\
\text { validity }\end{array}$ & $\begin{array}{l}\text { Pearson's correlation } \\
\text { coefficient }\end{array}$ \\
\hline Age & 0.025 & -0.115 & 0.143 & -0.075 & 0.987 & -0.021 \\
\hline Family number & 0.234 & 0.61 & 0.921 & -0.005 & 0.008 & -0.135 \\
\hline
\end{tabular}


and sometimes results similar to the present study have been reported that among possible reasons for this difference, we can point to the difference in studied populations. In most studies, treatment-seeking behavior has been examined on a special problem or illness that its intensity based on findings of different studies has been effective on treatment-seeking behavior. The level of studied regions development and their demographic and economic features are possibly among reasons of different treatment-seeking patterns.

Chuma et al. study in 2007 showed that self-medication using medicines purchased from drugstore or shop is the most important source of treating acute diseases. Self-medication in chronic diseases was very lower since most of them were not treated which somewhat confirms the present study findings. 288 responders $(75.8 \%)$ reported suffering from illness during the past 6 months. Among them, $70.7 \%$ had acute illness and only $29.3 \%$ had suffered chronic illness and most people needed primary cares and not specialized

Table 4: Examining the behavior of referring to therapist and self-medication of people based on demographic and economic features

\begin{tabular}{|c|c|c|c|c|}
\hline \multirow[t]{2}{*}{$\begin{array}{l}\text { Independent } \\
\text { variables }\end{array}$} & \multicolumn{2}{|c|}{ Self-medication } & \multicolumn{2}{|l|}{$\begin{array}{l}\text { Referring to } \\
\text { therapist }\end{array}$} \\
\hline & SD \pm median & $\mathbf{n}$ & SD \pm median & $\mathbf{n}$ \\
\hline \multicolumn{5}{|l|}{ Living place } \\
\hline City & $2.68 \pm 0.75$ & 304 & $2.2 \pm 0.59$ & 304 \\
\hline Village & $2.44 \pm 0.82$ & 76 & $2.07 \pm 0.60$ & 76 \\
\hline Total & $\begin{array}{l}2.63 \pm 0.77 \\
p=0.016\end{array}$ & 380 & $\begin{array}{l}2.19 \pm 0.54 \\
p=0.027\end{array}$ & 380 \\
\hline \multicolumn{5}{|l|}{ Income rate } \\
\hline $\begin{array}{l}<700,000 \text { Too } \\
\text { mans }\end{array}$ & $2.63 \pm 0.93$ & 110 & $2.14 \pm 0.57$ & 110 \\
\hline $\begin{array}{l}\text { Between } 700,000 \\
\text { and } 1.5 \text { million }\end{array}$ & $2.68 \pm 0.74$ & 189 & $2.26 \pm 0.50$ & 189 \\
\hline $\begin{array}{l}\text { Between } 1.5 \text { and } \\
2.3 \text { million }\end{array}$ & $2.57 \pm 0.60$ & 55 & $2.22 \pm 0.65$ & 55 \\
\hline & $\mathrm{p}=0.38$ & & $\mathrm{p}=0.282$ & \\
\hline \multicolumn{5}{|l|}{ Housing status } \\
\hline Owner & $2.60 \pm 0.79$ & 313 & $2.1 \pm 0.53$ & 313 \\
\hline Tenant & $2.76 \pm 0.64$ & 65 & $2.44 \pm 0.55$ & 67 \\
\hline Total & $2.63 \pm 0.77$ & 380 & $2.19 \pm 0.54$ & 380 \\
\hline
\end{tabular}

SD: Standard deviation treatment. Findings show that family physician had been responded to primary needs. On the other hand, existence of diverse plant coverage and a large number of old hand groceries in the city and people trust to their treatment have caused people to $64.7 \%$ use herbal medicines during self-medication.

In Pourreza study, only $13.5 \%$ of patients in the first contact point referred general physician. Mohagegh et al. study in 2012 showed that $74.3 \%$ of people in the first place refer to physician clinic for receiving services. A high percent of these references is related to specialists. The mentioned studies' results are inconsistent with the present study.

$68.4 \%$ of responders selected family physician as the first referral to service providers and only $2.6 \%$ of people referred to physician clinic. The results show the impact of implementing urban family physician plan in logical and sensible use of health services, and these study results, consistent with Starfield study, state that $75-85 \%$ of patients' need primary and specialized care during 1 year and referring to specialist is only $10-12 \%$ and reference to higher care levels is necessary just in $5 \%$ of cases.

Unlike Nasirianpour study (2016) which specified that age is not effective on treatment-seeking behavior of people suffering from transferred sexual infection, the present study showed that age has an inverse relation with inattention to treatment behavior. Older people are less inattentive to treatment. Inconsistent with the present study, in O'Neill et al. study, middle-aged and elderly used natural treatments for weakness and weariness while younger responders due to not liking flavor of herbal medicines preferred to prepare drug from drugstores or refer to health-care centers.

Pourreza study (2009) showed that the ratio of proceeding to treatment in old people ( 9 older than 60 years old) to age group 18-39 years old is 2.5 which somewhat consistent with this study results. Possibly, older people due to the reduction of ability are aware that inattention to problem could have more serious consequences for them and comparing younger people are less inattentive to treatment.

Place of living is the only variable of this study that three treatmentseeking behaviors are statistically different based on it. Consistent with this study, Chuma et al. (2007) introduced place of living among factors effective on treatment-seeking behavior, with this difference that $20.1 \%$ of people in rural regions and $9.3 \%$ of people in urban regions who

Table 5: Examining the behavior of inattentive to treatment based on demographic and economic features

\begin{tabular}{|c|c|c|c|c|c|c|}
\hline \multirow[t]{2}{*}{ Independent variables } & \multicolumn{6}{|c|}{ The rates of inattentiveness to treatment } \\
\hline & Very low & Low & Medium & High & Very high & Average \\
\hline \multicolumn{7}{|l|}{ Place of living } \\
\hline City & 94 & 67 & 107 & 30 & & 2.29 \\
\hline Village & 34 & 24 & 9 & 8 & 1 & 1.92 \\
\hline Total & $\begin{array}{l}128 \\
p=0.002\end{array}$ & 91 & 116 & 38 & 7 & 2.22 \\
\hline \multicolumn{7}{|l|}{ Income rate } \\
\hline$<700,000$ Toomans & 21 & 49 & 28 & 10 & 2 & 2.3 \\
\hline Between 700,000 and 1.5 million & 47 & 48 & 66 & 23 & 5 & 2.42 \\
\hline Between 1.5 and 2.3 million & 16 & 17 & 18 & 4 & 0 & 2.18 \\
\hline Between 2.3 and 3 million & 4 & 13 & 4 & 1 & 0 & 2.09 \\
\hline$>3$ million & 3 & 1 & 0 & 0 & 0 & 1.25 \\
\hline Total & $\begin{array}{l}91 \\
p=0.035\end{array}$ & 128 & 116 & 38 & 7 & 2.31 \\
\hline \multicolumn{7}{|l|}{ Insurance status } \\
\hline Without insurance & 55 & 37 & 53 & 19 & 5 & 2.3 \\
\hline Armed forces & 6 & 8 & 17 & 2 & 1 & 2.53 \\
\hline Social security & 2 & 0 & 5 & 1 & 0 & 2.62 \\
\hline Treatment services & 2 & 0 & 5 & 1 & 0 & 2.62 \\
\hline Total & $\begin{array}{l}125 \\
p=0.041\end{array}$ & 88 & 114 & 38 & 7 & 2.23 \\
\hline
\end{tabular}


reported suffering from acute illness during the 2 weeks before study, did not seek any treatment and about chronic illness a similar pattern was observed (56.9 villagers, 44.9 citizens).

In the present study, the behavior of inattention to treatment among city dwellers (average 1.9). The statistics provided below possibly justifies this behavior.

The rate of suffering from illness in both regions is $75 \%$, and $75 \%$ of villagers and $70 \%$ of citizens reported suffering from acute illness. $51.7 \%$ of village dwellers declared that their illness has not been intense (36.1\% of citizens). Possibly, regarding the reported intensity and severity in rural regions and active presence of family physician and periodical visits and continuous training activity of social workers, inattention to treatment has become less in village dwellers. The reported intensity and severity show that possibly most village dwellers need primary and not specialized cares so that the rate of referring to family physician in urban and rural population is exactly similar (average 3.3) and referring to other service provider centers except clinic is more in urban population, and this points confirms that citizens more refer to therapist.

Villagers on average refer to drugstore rarely (2.2) and citizens moderately (2.6) and due to easier access for purchasing drugs go to drugstore without a physician prescription. This issue could be the reason of more tendency of city population to self-medication treatment.

Consistent with the results of this study, Pourreza et al. study showed that with increasing of one person to family members, the possibility to refer to health-care centers has decreased. However, Mohaghegh et al. (2012) reported that no significant difference was found between the number of family members with none of treatment-seeking behaviors.

It seems that increasing of family members both in respect of life costs impact and regarding this point that using health-care services is enumerated financial load and both in respect of increasing family responsibility and shortage of enough time for referring to service providers which is a time-consuming process, leads to reduction of referring to therapist.

Consistent with the present study, Hasnain et al. study (2014) showed that low levels of training and very low income of worker women in Bangladesh have led to their vulnerability to illnesses and influence health-seeking behavior and harms the ability to acquire income and also the results of Adhikari and Rijal study in 2014 showed that $35 \%$ of old people due to poverty do not follow treatment through health-care institutes.

While Kavousi and Zareh (2012) and Watejen et al. (2015) stated that there is no statistically significant relation between income rate and treatment-seeking behavior.

The present study findings showed that people with higher income (fourth and fifth classes) less refer to therapist and these people only constitute $6.9 \%$ of responders. It seems that non-intensity of illness and self-employment and working for long hours is an inhibiting obstacle for referring to therapist in this group of people. On the other hand, it seems that physician shortage and equipment in towns and economic problem and non-intensity of illness and dissatisfaction with treatment quality are among its reasons.

Kavousi and Zareh (2012) in a cross-sectional study with the aim of examining treatment-seeking behavior found out that dwellers of Marvdasht city who had private home, used higher levels of health services which indicates higher economic ability and more financial access to higher levels of service and in the present study, consistent with Zareh study, a significant difference was found between housing status with referring to therapist. With this difference that tenants proceed to treatment more moderately than house owners. Possibly, tenants due to perceiving this issue that not treatment seeking could impose more financial consequences to the family, at the time of encountering with illness, follow treatment from service provider centers.

Rasoulinejad et al. (2005) and Waetjen et al. (2015) found out that there is no significant relation between payment method and treatment-seeking behavior. Pourreza et al. (2009) and Mohegh et al. (2012) and Kavousi and Zareh (2012) confirmed that insurance status and its type will be one of factors effective on selection of health service providers by people. In the present study, no statistical difference was found between insurance type and referring to treatment and selfmedication behaviors, but inattention to treatment behavior is different in various insurances so that people covered by social security had the least inattention and people covered by relief committee the highest inattention to treatment. Health insurance and armed forces were in the second and third rank. Most people covered by health insurance do not pay insurance fee, and on the other hand, are not aware of service which they receive by offering insurance booklet for free and non-awareness from advantages of health insurance booklet could be the reason of intention of this insurance covered people comparing social security. Non-joining of armed force insurance to urban family physician plan and economic problems and low ability of relief committee insured people could be mentioned among reasons of their inattention to treatment comparing other insurances. In the present study, no significant difference was found between gender, marital status, education level, and occupation status with treatment-seeking behavior

\section{CONCLUSION}

In the present study, people moderately reported self-medication. Most people selected using herbal drugs as the first step for self-medication, but their free access to medicines without physician prescription is considerable and adopting some strategies for access limitation to some medicines by authorities is necessary.

The study findings about self-medication reasons and inattention to treatment attract more attention of managers to appropriate distribution of specialists and equipment in city and providing strategies for increasing satisfaction and trust to governmental sections. Insurance coverage of $97.9 \%$ people shows the impact of implementing policies imparted by leadership in 2014 about making treatment base insurance public and full coverage of treatment base needs by insurances.

5 years' experience of implementing urban family physician has caused a considerable percent of people select family physician as the first step of referring to therapist which indicates gradual modification of reference system and significance of implementing urban family physician in other provinces. Among the most important factors determining treatment-seeking behavior are age, family members, housing status, monthly income rate, and people treatment insurance type. We can say that people with different economic and demographic features show different behaviors when treatment seeking. Intensity and severity of illness they are encountered, and features and rate of accessible services change treatment selection route by people. Evaluation and perception of significance of total factors by people helps the management of conditions and adoption of correct and proper decision at the time of illness accession and since about $94 \%$ of studied people when a problem occurs were seeking to acquire information about illness and treatment methods, we should not ignore public and simple training role in the format of various groups in forming correct behavior

\section{LIMITATIONS}

Regarding that people self-evaluation information base is suffering from illness, then, the possibility of encounter is low and high of people 
reporting from illness accession. It is suggested that the study results to be used with more cautious. Responders sensitivity for exact statement of income rate due to simultaneousness of the plan with omission of some people form subside list and time and space limitation.

\section{ACKNOWLEDMENT}

This article is the result of part of M. A thesis of health and treatment services management of Fars Research and Technology Azad University. Hereby, we appreciate the participation of personnel in research plan and all who helped us in various stages of the research.

\section{REFERENCES}

1. Adamson J, Ben-Shlomo Y, Chaturvedi N, Donovan J. Ethnicity, socioeconomic position and gender - Do they affect reported health-care seeking behaviour? Soc Sci Med 2003;57(5):895-904.

2. Chowdhury F, Khan IA, Patel S, Siddiq AU, Saha NC, Khan AI, et al. Diarrheal illness and healthcare seeking behavior among a population at high risk for diarrhea in Dhaka, Bangladesh. PLoS One 2015;10(6):e0130105.

3. Adhikari D, Rijal D. Factors affecting health seeking behavior of senior citizens of Dharan. J Nobel Med Coll 2015;4(1):57-63.

4. Atashbahar O, Bahrami MA, Asqari R, Fallahzadeh H. An examination of treatment seeking behavior affecting factors: A qualitative study in Iran. World Appl Sci J 2013;25(5):774-81.

5. Ansong E. The association between household consumer durable assets and maternal health-seeking behavior in Ghana. Women Health 2015;55(5):485-504.

6. Dixon-Fyle S, Gandhi S, Pellathy T, Spatharou A. Changing patient behavior: The next frontier in healthcare value. Heart Int 2012;12:64-73.

7. Andersen R, Newman JF. Societal and individual determinants of medical care utilization in the United States. Milbank Q 2005;83(4):1-28.

8. Hasnain G, Akter M, Sharafat SI, Mahmuda A. Morbidity patterns, nutritional status, and healthcare-seeking behavior of female garment workers in Bangladesh. Electron Physician 2014;6(2):801-7.

9. Dhawan A, Chopra A, Ambekar A, Ray R. Treatment seeking behavior of inhalant using street children: Are we prepared to meet their treatment needs. Indian J Psychol Med 2015;37(3):282-7.

10. Chuma J, Gilson L, Molyneux C. Treatment-seeking behaviour, cost burdens and coping strategies among rural and urban households in Coastal Kenya: An equity analysis. Trop Med Int Health 2007;12(5):673-86.

11. Boerema AM, Kleiboer A, Beekman AT, van Zoonen H, Dijkshoorn H, Cuijprers $\mathrm{P}$, et al. Determinants of help-seeking behavior in depression: A cross-sectional study. BMC Psychiatry 2016;16(1):78.

12. Waetjen LE, Xing G, Johnson WO, Melnikow J, Gold EB; Study of Women's Health Across the Nation (SWAN). Factors associated with seeking treatment for urinary incontinence during the menopausal transition. Obstet Gynecol 2015;125(5):1071-9.

13. Starfield B. Primary Care: Balancing Health Needs, Services, and Technology. USA: Oxford University Press; 1998.

14. Nasirian M, Karamouzian M, Kamali K, Nabipour AR, Maghsoodi A, Nikaeen R, et al. Care seeking patterns of STIs-associated symptoms in Iran: Findings of a population-based survey. Int J Health Policy Manag 2016;5(1):5-11.

15. O'Neill S, Gryseels C, Dierickx S, Mwesigwa J, Okebe J, d'Alessandro U, et al. Foul wind, spirits and witcheraft: Illness conceptions and health-seeking behaviour for malaria in the Gambia. Malar J 2015;14:167.

16. Soleimani MA, Negarandeh R, Bastani, Farideh. Explaining self-care process in people with Parkinson: A background theory study. Acad J 2015;21(1):6-22.

17. Mohegh, Mahta, Pourreza, Rahimi, Sari A, Moghadam N. Examining treatment seeking behavior in Zoroastrians living in Yazdcity in 2008, hospital. ??? 2012;11(3):61-72.

18. Pourreza A, Kheibari R, Arab M, Sari AA, Rahimi A, Toll A. Examining treatment seeking behavior in Tehran city dwellers and factors effective on it. Health Fac Health Res Inst J 2009;2(7):1-13.

19. Zahra, K, Fatemeh, Z. Using Health System Services in Families of Fars Province Rural Region (Short Report)

20. Nejad R, Asghar S, Nejad R, Alsadat M, Shaeri. Examining the patients behavior at the time of need to treatment services and factors related to it in Kashan city, 2002, medical sciences and healthcare services university of Kashan, Feiz Seasonal. ??? 2005;1:2-9. 